\title{
Are hygiene standards useful in assessing infection risk?
}

White $\mathrm{L}^{1}$, Dancer $\mathrm{SJ}^{1}$ *, Robertson $\mathrm{C}^{2}$ and McDonald $\mathrm{J}^{3}$

Depts. of Microbiology ${ }^{1}$ and Anaesthetics ${ }^{3}$, Southern General Hospital, 1345 Govan

Road, Glasgow G51 4TF, Scotland

Department of Statistics \& Modelling Science ${ }^{2}$, University of Strathclyde, Glasgow

G1 1XH, Scotland

*Corresponding author: Tel: +44-141-201-1705 Fax: +44-141-201-1704

E-mail: stephanie.dancer@sgh.scot.nhs.uk

Keywords: Hospital cleaning; clinical environment; staphylococci; hospital-acquired infection; intensive care unit

Running head: Hygiene standards and infection risk 


\begin{abstract}
Background. We monitored the surface level cleanliness of a five-bedded surgical intensive care unit (SICU) over a ten-week period in order to evaluate proposed hygiene standards.
\end{abstract}

Methods. Ten environmental sites within SICU were sampled twice weekly along with collection of clinical and patient activity data. The standards designate aerobic colony counts $(\mathrm{ACCs})>2.5 \mathrm{cfu} / \mathrm{cm}^{2}$ from hand-touch sites and the presence of Staphylococcus aureus as hygiene failures.

Results. Nearly a quarter of 200 samples failed the standards, mostly from hand-touch sites on curtains, beds and medical equipment. The total number of fails each week was associated with bed occupancy $(\mathrm{p}=0.04)$, trending towards association with SICU-acquired infections $(\mathrm{p}=0.11)$. Environmental S.aureus was associated with the proportion of beds occupied $(\mathrm{p}=0.02)$. Indistinguishable genotypes were found between patient and environmental staphylococci, with timescales supporting staphylococcal transmission in both directions.

Conclusions. Hygiene standards based on microbial growth levels and the presence of S.aureus reflect patient activity and provide a means to risk manage infection. They also exposed a staphylococcal reservoir that could represent a more tangible risk to patients. Standards for surface level cleanliness deserve further evaluation. 


\section{Introduction}

Standards for surface level cleanliness have been proposed, based on internationally recognised standards used by the food industry. ${ }^{1,2}$ An important distinction is that the hospital standards specify surfaces frequently touched by hands. They designate

aerobic colony counts (ACCs) $>2.5 \mathrm{cfu} / \mathrm{cm}^{2}$ from hand-touch sites and the presence of pathogens including Staphylococcus aureus as hygiene failures. ${ }^{1}$

This project aimed to assess surface level cleanliness in a surgical intensive care unit (SICU) using proposed standards with S.aureus as indicator. The main objective was to test their value against patient activity and the risk of HAI.

\section{Methods}

SICU is a five-bedded ward with one side room in a UK teaching hospital. Four nearpatient 'hand-touch' sites (cardiac monitor buttons, bed, curtain and work station), and four others (computer keyboard, telephone, blood-gas analyser and staff chair) were screened twice weekly over the ten-week period at different times. A sink and floor were included as non-hand-touch sites. SICU has one cleaner for 4 hours a day responsible for the general environment not including clinical equipment.

Bed occupancies, number of admissions and average APACHE II admission score were obtained weekly. SICU-acquired infection was confirmed according to the definitions established by CDC, and patient staphylococci were stored on preservation beads. ${ }^{3}$ Staffing levels were not recorded. ${ }^{4}$ Patients are routinely screened on admission and at weekly intervals for methicillin-resistant S. aureus (MRSA). 
Dipslides coated with nutrient and Baird Parker agars (Biotrace $®$, Bridgend, UK) were incubated at $30^{\circ} \mathrm{C}$ in air for 48 hours after sampling. ${ }^{4,5}$ Microbial growth was quantified as $<2.5 \mathrm{cfu} / \mathrm{cm}^{2}=$ scanty growth; $2.5-12 \mathrm{cfu} / \mathrm{cm}^{2}=$ light growth; and 12$40 \mathrm{cfu} / \mathrm{cm}^{2}=$ moderate growth, according to manufacturer's recommendations. Staphylococci were identified using established methods, and tested for antibiotic susceptibilities using Clinical Laboratory Standards Institute guidelines. Isolates were stored on beads as before. PFGE on all staphylococci was performed according to the standard operating procedures of the Scottish MRSA Reference Laboratory. ${ }^{6}$

The standard set for finding a potential pathogen is $\left\langle 1 \mathrm{cfu} / \mathrm{cm}^{2}{ }^{1}\right.$ We chose S.aureus, including meticillin-resistant S.aureus (MRSA), to indicate hygiene failures. A second standard states that the total aerobic colony count (ACC) from a hand-touch site should not exceed $2.5-5 \mathrm{cfu} / \mathrm{cm}^{2}{ }^{1}$ High levels suggest insufficient cleaning, mask the presence of a pathogen or imply more chance of finding epidemiologically related pathogens, e.g. CNS and S. aureus. A hygiene failure was therefore defined as a site with an ACC greater than $2.5 \mathrm{cfu} / \mathrm{cm}^{2}$ and/or any site harbouring S.aureus/MRSA.

Growth level failures and presence of S.aureus/MRSA from the same site at the same time were counted as a single hygiene failure. Fisher's Exact test was used to test associations and Exact binomial methods for confidence intervals. Exact logistic regression models assessed the relationship between growth level and organism failures and site and week. Our main aim was to test the proportion of failures across all hand-touch sites and whether this was related to ward or site characteristics each week. The 5\% significance level was used for the primary hypothesis with $95 \%$ confidence intervals. There were too few data for multivariate logistic regression. 
Statistical analysis was carried out using Splus 7.0. (S-PLUS ${ }^{\circledR} 7.0$ for Windows

ENTERPRISE DEVELOPER, 2005, Insightful Corporation) and LogXact 4.1

(LogXact 4.1, Cytel Software Corporation 1989-2000, Cytel Inc. Cambridge, Mass).

\section{Results}

SICU admitted 59 patients during the ten-week study. Table 1 shows the number of weekly admissions, bed occupancy rates, mean admission APACHE II scores, number of beds occupied at each sampling occasion, number of SICU-acquired infections, growth levels $>2.5 \mathrm{cfu} / \mathrm{cm}^{2}$ and S.aureus/MRSA isolation from eight handtouch sites. Twenty out of 59 (34\%) patients developed SICU-acquired infection, 14 of which provided five MSSA isolates, three MRSA and six CNS from tissue, sputum, wounds and blood.

Samples were taken from 160 hand-touch and 40 non-hand-touch sites. Growth levels from sink and floor exceeded the standards once, with just two S.aureus recovered from the floor. In contrast, growth levels from hand-touch sites exceeded the standards on 25 occasions, along with recovery of 25 S.aureus and four MRSA. Overall, there were hygiene failures from $23.0 \%$ of 200 samples (95\% confidence interval (CI) 17.7\%, 29.3\%) with significantly more failures from hand-touch sites compared with non-hand-touch sites, 27.5\% (95\% CI 21.2\%, 34.9\%) against 5\% $(95 \%$ CI $1.4 \%, 16.5 \%), \mathrm{p}=0.008$. Hand-touch sites were cleaner than the floor or sink. Is this last sentence correct. I think it should be the other way round. Hand touch sites were less clean than the floor or sink. Cardiac monitor buttons, bed, curtain and blood gas analyser failed the standards more often, with the curtain (6 
isolates), chair (5 isolates) and bed (4 isolates) providing most S.aureus/MRSA. Growth levels at specific sites and presence of S.aureus/MRSA did not appear to be related.

Growth failures $(\mathrm{p}=0.005)$ and total hygiene fails $(\mathrm{p}=0.01)$ but not the presence of S.aureus/MRSA $(\mathrm{p}=0.17)$ varied significantly across the eight hand-touch sites. These variations were not related to a difference between near-patient sites and those further away ( $\mathrm{p}=0.38$ for growth levels) but resulted from the workstation, habitually beside an empty bed which had no hygiene failures. Excluding this site suggests that nearpatient hand-touch sites may be more likely to fail the standards $(\mathrm{p}=0.09)$.

The proportion of hand-touch sites with a growth level failure did not depend upon the sampling week $(\mathrm{p}=0.76)$ and there was no evidence that growth failures were related to admissions $(\mathrm{p}=0.22)$, APACHE II score $(\mathrm{p}=0.31)$ or proportion of beds occupied ( $\mathrm{p}=0.97$ ) (Table 1). S.aureus/MRSA on hand-touch sites were not influenced by admissions $(\mathrm{p}=0.61)$ but there may be a trend towards association with SICUacquired infections $(\mathrm{p}=0.11)$. The odds ratio of a hand-touch site failing the standards was 3.16 (95\% CI 1.01-13.23) times greater if there was at least one SICU-acquired infection compared to no infections. There was evidence that S.aureus/MRSA were associated with the proportion of beds occupied $(\mathrm{p}=0.02)$; in addition, the total number of hygiene failures per week was positively associated with bed occupancy $(\mathrm{p}=0.04)$.

PFGE typing demonstrated one patient S.aureus to be indistinguishable from three S.aureus from bed, monitor buttons and analyser. There were similar patterns between 
two groups of two environmental S.aureus (curtains and computer). Two unique patient MRSA were each indistinguishable from two MRSA from the chair, one found before the patient's strain was characterised and the other afterward (Table 2). Two patient CNS were indistinguishable from three CNS from bed, analyser and workstation. Indistinguishable patterns were also found between three environmental CNS from workstation and curtain. PFGE thus revealed five patient isolates indistinguishable from eight environmental isolates and three groups of indistinguishable environmental isolates (data not shown), with timescales of finding unique organisms from both sources supporting bi-directional transmission (Table 2).

\section{Discussion}

These proposed hygiene standards provided data that could be measured against patient variables, including incidence of hospital-acquired infection. The results suggest that they might be useful in monitoring cleaning efficacy, particularly of highrisk hand-touch sites, and in assessing infection risk to patients. We also identified specific staphylococcal reservoirs in the environment, indistinguishable strains from which later appeared in patients. ${ }^{4,7}$ Staff were not screened during this study, however, which means that a carrier role by staff cannot be excluded in any transmission hypotheses. ${ }^{4}$ Indistinguishable strains were recovered from different sites around the ward, sometimes weeks apart. ${ }^{4,7}$

Several studies have indicated the importance of hand-touch sites as likely sources of HAI transmission via hands, and there may well be benefits from targeted cleaning of these sites. ${ }^{1,9}$ The decontamination of clinical equipment is a nursing responsibility 
but nurses' main priority is patient care, which may supersede cleaning duties when they are busy. ${ }^{4}$ It is plausible that a sudden increase in workload leads to increased microbial levels in the environment and increased risk of infection for patients. ${ }^{4,10}$ This supports the apparent association between total number of hygiene failures, including S.aureus/MRSA, and bed occupancy found in this study.

In conclusion, proposed hygiene standards based on microbial growth levels and the presence of S.aureus reflects patient (and staff) activity, highlights sites that require extra cleaning and may help to risk manage infection. They also exposed a staphylococcal reservoir that could represent a more tangible risk to patients. Targeted cleaning could be an important control factor for staphylococcal acquisition.

\section{Acknowledgements}

Thanks are due to staff in SICU and Microbiology, and Professor Niall Logan (Glasgow Caledonian University) who supervised the MSc thesis from which this work was extracted. Tim Brett (Health Protection Scotland) provided financial support from NHS Scotland and Donald Morrison kindly supervised PFGE typing. The work was presented at the $17^{\text {th }}$ ECCMID, Munich, 31 March-3 April 2007. 


\section{References}

1. Dancer SJ. How do we assess hospital cleaning? A proposal for microbiological standards for surface hygiene in hospitals. J Hosp Infect 2004; 56: $10-5$.

2. Malik RE, Cooper RA, Griffith CJ. Use of audit tools to evaluate the efficacy of cleaning systems in hospitals. Am J Infect Control 2003; 31: 181-7.

3. Emori TG, Culver DH, Horan TC, Jarvis WR, White JW, Olson DR, et al. National nosocomial infections surveillance (NNIS): description of surveillance methods. Am J Infect Control 1991; 19:19-35.

4. Dancer SJ, Coyne M, Speekenbrink A, Samavedam S, Kennedy J, Wallace PGM. Methicillin-resistant Staphylococcus aureus (MRSA) acquisition in an intensive care unit (ICU). Am J Infect Control 2006; 34: 10-7.

5. Obee P, Griffith CJ, Cooper RA, Bennion NE. An evaluation of different methods for the recovery of meticillin-resistant Staphylococcus aureus from environmental surfaces. J Hosp Infect 2007; 65: 35-41.

6. Macfarlane L, Walker J, Borrow R, Oppenheim BA, Fox AJ. Improved recognition of MRSA case clusters by the application of molecular subtyping using pulsed-field gel electrophoresis. J Hosp Infect 1999; 41: 29-37.

7. Hardy KJ, Oppenheim BA, Gossain S, Gao F, Hawkey PM. A study of the relationship between environmental contamination with methicillin-resistant Staphylococcus aureus (MRSA) and patients' acquisition of MRSA. Infect 
Control Hosp Epidemiol 2006; 27:127-32.

8. Sexton T, Clarke P, O’Neill E, Dillane T, Humphreys H. Environmental reservoirs of methicillin-resistant Staphylococcus aureus in isolation rooms: correlation with patient isolates and implications for hospital hygiene. J Hosp Infect 2006; 62: 187-94.

9. Bhalla A, Pultz NJ, Gries DM, Ray AJ, Eckstein EC, Aron DC, et al. Acquisition of nosocomial pathogens on hands after contact with environmental surfaces near hospitalised patients. Infect Control Hosp Epidemiol 2004; 25: 164-7.

10. Hugonnet S, Chevrolet J-C, Pittet D. The effect of workload on infection risk in critically ill patients. Crit Care Med 2007; 35: 76-81. 
Table 1: Weekly patient admissions, SICU bed occupancies, mean Apache II, SICU-acquired infections, growth level fails and number of S.aureus/MRSA from hand-touch sites on SICU

\begin{tabular}{|c|c|c|c|c|c|c|c|c|}
\hline Week & $\begin{array}{l}\text { Patients } \\
\text { admitted }\end{array}$ & $\begin{array}{c}\text { Beds } \\
\text { occupied on } \\
\text { each } \\
\text { sampling } \\
\text { occasion }\end{array}$ & $\begin{array}{c}\text { Weekly } \\
\text { bed } \\
\text { occupancy }\end{array}$ & $\begin{array}{c}\text { Mean } \\
\text { Apache } \\
\text { II }\end{array}$ & $\begin{array}{c}\text { No. of } \\
\text { SICU- } \\
\text { acquired } \\
\text { infections }\end{array}$ & $\begin{array}{c}\text { Growth } \\
\text { level fail } \\
(>2.5 \mathrm{cfu} \\
\left./ \mathrm{cm}^{2}\right)\end{array}$ & $\begin{array}{c}\text { No. of } \\
\text { MSSA } \\
\text { \&/or } \\
\text { MRSA }\end{array}$ & $\begin{array}{c}\text { Total } \\
\text { no. of } \\
\text { hygiene } \\
\text { fails } *_{\infty}\end{array}$ \\
\hline \multirow[t]{2}{*}{1} & \multirow[t]{2}{*}{5} & 4 & \multirow[b]{2}{*}{$86.1 \%$} & \multirow[b]{2}{*}{21.6} & \multirow[b]{2}{*}{4} & \multirow[b]{2}{*}{3} & \multirow[b]{2}{*}{6} & \multirow[b]{2}{*}{7} \\
\hline & & 4 & & & & & & \\
\hline \multirow{2}{*}{2} & \multirow{2}{*}{4} & 3 & \multirow[b]{2}{*}{$70.5 \%$} & \multirow[b]{2}{*}{17.9} & \multirow[b]{2}{*}{3} & \multirow[b]{2}{*}{3} & \multirow[b]{2}{*}{1} & \multirow[b]{2}{*}{4} \\
\hline & & 4 & & & & & & \\
\hline \multirow{2}{*}{3} & \multirow{2}{*}{7} & 4 & \multirow[b]{2}{*}{$80.1 \%$} & \multirow[b]{2}{*}{19.9} & \multirow[b]{2}{*}{1} & \multirow[b]{2}{*}{1} & \multirow[b]{2}{*}{5} & \multirow[b]{2}{*}{5} \\
\hline & & 4 & & & & & & \\
\hline \multirow{2}{*}{4} & \multirow{2}{*}{5} & 3 & \multirow[b]{2}{*}{$75.7 \%$} & \multirow[b]{2}{*}{26.4} & \multirow[b]{2}{*}{2} & \multirow[b]{2}{*}{2} & \multirow[b]{2}{*}{3} & \multirow[b]{2}{*}{5} \\
\hline & & 3 & & & & & & \\
\hline \multirow{2}{*}{5} & \multirow{2}{*}{6} & 2 & & & & & & \\
\hline & & 2 & $41.2 \%$ & 18.8 & 0 & 3 & 1 & 3 \\
\hline 6 & 8 & 3 & & & & & & \\
\hline 6 & 8 & 4 & $80.0 \%$ & 20.4 & 2 & 3 & 2 & 5 \\
\hline 7 & 3 & 3 & & & & & & \\
\hline 7 & 3 & 3 & $71.7 \%$ & 15.6 & 3 & 4 & 3 & 6 \\
\hline 8 & 8 & 2 & & & & & & \\
\hline 8 & 8 & 1 & $51.7 \%$ & 14.7 & 0 & 1 & 1 & 1 \\
\hline & & 2 & & & & & & \\
\hline 9 & 6 & 1 & $73.4 \%$ & 24.0 & 3 & 3 & 3 & 4 \\
\hline 10 & 7 & 3 & & & & & & \\
\hline 10 & 7 & 3 & $84.8 \%$ & 21.3 & 2 & 2 & 2 & 4 \\
\hline $\begin{array}{l}\text { Totals/ } \\
\text { Mean }\end{array}$ & 59 & 3 & 71.52 & 20.06 & 20 & 25 & 27 & $44^{* *}$ \\
\hline
\end{tabular}

*A growth level failure and the presence of S.aureus/MRSA at the same site at the same time are counted as one single hygiene failure; ** Over one quarter of handtouch sites failed the hygiene standards during the study; $\infty$ Definition of 'hygiene fail' from Dancer (2004) and Malik et al (2003). ${ }^{1,2}$ 


\section{Table 2: Sites and dates of staphylococcal isolates from SICU indistinguishable by PFGE}

\begin{tabular}{|c|c|}
\hline \multicolumn{2}{|l|}{ S.aureus } \\
\hline \multicolumn{2}{|l|}{ Site of sample } \\
\hline \multicolumn{2}{|c|}{ Patient } \\
\hline \multicolumn{2}{|c|}{ Blood gas analyser } \\
\hline \multicolumn{2}{|c|}{ Bed frame } \\
\hline \multicolumn{2}{|c|}{ Cardiac monitor buttons } \\
\hline \multicolumn{2}{|c|}{ Bedside curtain } \\
\hline \multicolumn{2}{|c|}{ Computer keyboard } \\
\hline \multicolumn{2}{|c|}{ Bedside curtain } \\
\hline \multicolumn{2}{|l|}{ Bedside curtain } \\
\hline \multicolumn{2}{|l|}{ MRSA } \\
\hline Site of sample & Date of sample \\
\hline Staff chair & $08 / 11 / 05$ \\
\hline Patient* & $28 / 12 / 05$ \\
\hline Patient & $18 / 10 / 05$ \\
\hline Staff chair & $15 / 11 / 05$ \\
\hline \multicolumn{2}{|l|}{ CNS } \\
\hline Site of sample & Date of sample \\
\hline Patient & $14 / 11 / 05^{1}$ \\
\hline Bed frame & $14 / 11 / 05$ \\
\hline Work station & $15 / 11 / 05$ \\
\hline Blood gas analyser & $12 / 12 / 05$ \\
\hline Patient* & $26 / 12 / 05$ \\
\hline Work station & $07 / 11 / 05$ \\
\hline Bedside curtain & $13 / 12 / 05$ \\
\hline Bedside curtain & $20 / 12 / 05$ \\
\hline
\end{tabular}

One patient S.aureus was identified one and eight days before the same strain was found from three environmental sites. Of two different patient MRSA isolates, one was identified seven weeks before its related strain was isolated from a chair but a separate unique strain was identified four weeks after the chair isolate. One patient CNS was found from two near-patient sites on the same day and a day later; a different and unique CNS was found on the blood gas analyser two weeks before an indistinguishable strain was recovered from a patient. 
